Universidad de Guadalajara

Derecho Global. Estudios sobre Derecho y Justicia

Año 4, núm 10, noviembre 2018- febrero 2019, pp. 127-152, ISNN: 2448-5128, e-ISNN: 2448-5136

https://doi.org/10.32870/dgedj.v0i10.198

\title{
La instrumentación de la reforma constitucional de 2017 en materia de justicia laboral y de seguridad social en México
}

\section{The implementation of the 2017 constitutional reform on labor justice and social security in Mexico}

\author{
Ángel Guillermo Ruíz Moreno \\ Universidad de Guadalajara, México \\ agruizm@ruizmoreno.com \\ Ángel Edoardo Ruíz Buenrostro \\ Universidad de Guadalajara, México \\ aeruizb@gmail.com
}

Recibido: 09/03/18 | Aceptado: 04/06/18

RESUMEN: Tras de un siglo de mantener la justicia tripartita como dogma jurídico en el Derecho del Trabajo, el Estado mexicano se aleja de él optando, en base a los resultados obtenidos en los «Diálogos por la Justicia Cotidiana», por cambiar de operador en materia de justicia, traspasando tan delicada función al Poder Judicial Federal y Locales en sus respectivas competencias y condenando a desaparecer a las Juntas de Conciliación y Arbitraje dependientes del Poder Ejecutivo, quitando así todo tinte político en la resolución de los conflictos laborales. Este cambio radical, el más trascendente en un siglo de existencia del mítico artículo 123 de nuestra Constitución Política Federal, tendrá muchos problemas en su instrumentación legal, al punto que ya se venció el plazo fijado para ello en el Decreto de reforma publicado el 24 de febrero de 2017.

PALABRAS CLAVE: justicia cotidiana, conciliación, negociación colectiva, registro sindical, Poder Judicial.

ABSTRACT: After a century of maintaining tripartite justice as a legal dogma in Labor Law, Mexico opts to change the operator in terms of justice, based on the results obtained in the «Diálogos por la Justicia Cotidiana», transferring such a delicate function to the Federal and Local Judiciary in their respective domain and condemning the Conciliation and Arbitration Boards, dependent on the Executive Power, to disappearance, thus removing all political influences in the resolution of labor conflicts. This radical change, the most transcendental in a century of existence of the legendary article 123 of our Federal Political Constitution, will have many problems in its legal implementation, just like we can conclude from the fact that its deadline published on 24 February 2017 in the reformation decree has already ended.

KEYWORDS: everyday justice, conciliation, collective bargaining, labor union registration, Judiciary. 


\section{SUMARIO}

I. El contexto de la reforma en materia de justicia laboral en México. II. Aspectos fundamentales de la reforma de 2017 a los artículos 107 y 123 apartado A, de la Constitución Política Mexicana. III. Las tareas pendientes por acometer por el Estado mexicano en materia de administración de justicia en seguridad social. IV. Breves conclusiones. Bibliografía.

\section{EI contexto de la reforma en materia de justicia laboral en México}

Con el principal propósito de adecuar el marco normativo vigente de nuestro sistema nacional de impartición de justicia, mediante un diagnóstico situacional en todo el país de la llamada justicia cotidiana, y contando con el apoyo de los Poderes Legislativo y Judicial federales así como de diversas organizaciones nacionales educativas e instituciones públicas y civiles, el 27 de noviembre de 2014 el Presidente Enrique Peña Nieto solicitó al Centro de Investigación y Docencia Económica (CIDE) que indagara acerca de las problemáticas existentes en los temas más comunes en los que se concentra la impartición de justicia nacional; le instruyó para que organizara foros de consulta, con especialistas de los diversos temas, sometidos a escrutinio a fin de elaborar un diagnóstico situacional consistente y objetivo con la idea de generar recomendaciones de reformas al marco legal existente para garantizarle a la sociedad un mejor servicio del Estado mexicano en la impartición de justicia cotidiana.

Así, en los denominados «Diálogos por la Justicia Cotidiana», ${ }^{1}$ efectuados con expertos de cada materia y convocados por el propio Gobierno Federal — que en la práctica realizó el CIDE durante 2015, junto con el Instituto de Investigaciones Jurídicas de la UNAM-, se abordó una diversidad de temas en materia de Derecho Civil, Mercantil, Penal y, claro, también en Derecho del Trabajo, en cuanto a la operación de tribunales y tareas propias de administración

1 Véase el PDF final, de los llamados «Diálogos de Justicia Cotidiana», en la siguiente liga web: https://www. gob.mx/cms/uploads/attachment/file/79028/Di logos Justicia_Cotidiana.pdf 
de justicia. El resultado fue recogido en foros en los que participaron más de 200 personas, provenientes de 26 prestigiadas instituciones de distintos sectores, como investigadores, académicos, abogados postulantes, representantes de la sociedad civil y de organismos autónomos, así como de los propios Poderes Ejecutivo, Legislativo y Judicial federales, quienes se reunieron durante casi cuatro meses para diagnosticar problemáticas y proponer soluciones concretas de mejora en el acceso de la población a la justicia cotidiana en todo el país.

Resultado de dicho proceso de diálogo y discusión sin precedentes, surgió la Iniciativa del 28 de abril de 2016 del Titular del Ejecutivo Federal, quien planteó al Congreso de la Unión reformas al inciso d) de la fracción $\mathrm{V}$ del artículo $107,{ }^{2}$ y especialmente profundas reformas al artículo 123 a las fracciones XVIII, XIX, XX, XXI; adiciones de una nueva fracción XXII Bis, así como a la fracción XXVII inciso b), y además un nuevo inciso c) de la fracción XXXI, todos de la Constitución Política de los Estados Unidos Mexicanos (CPEUM). ${ }^{3}$

El punto focal de dicha Iniciativa de reforma consistía en un hecho trascedente: cambiar al operador de la justicia laboral, quitándole su manejo al Poder Ejecutivo Federal y Locales, a fin de dejar dicho cometido al Poder Judicial en ambos ámbitos, un asunto de gran impacto en una materia de inevitables repercusiones políticas, económicas y sociales. La idea de fondo era contar con una mejor y más eficaz justicia social efectiva, que tutelara bajo el actual paradigma jurídico de los derechos humanos existente en México, los derechos irrenunciables e inalienables de los operarios subordinados a un patrón. Esto terminaría con el rezago y las malas prácticas observadas de la operación cotidiana de las Juntas federal y Locales de Conciliación y Arbitraje. Un necesario cambio

\footnotetext{
2 Por cierto, en dicho artículo 107 fracción V de la CPEUM, se encuentran contenidas las disposiciones de la procedencia del juicio de Amparo Directo, donde se propuso reformar el inciso d), para establecer lo siguiente: "En materia laboral, cuando se reclamen resoluciones definitivas que pongan fin al juicio dictadas por los tribunales laborales locales o federales o laudos del Tribunal Federal de Conciliación y Arbitraje de los Trabajadores al Servicio del Estado y sus homólogos en las entidades federativas. " Lo adelantamos porque no volveremos a tocar aquí este tema específico de reformas al artículo 107 Constitucional.

3 Consúltese el texto de dicha Iniciativa Presidencial del 28 de abril de 2016 y su Exposición de Motivos, en la siguiente liga web: https://www.gob.mx/justiciacotidiana/documentos/iniciativa-de-reforma-constitucionalen-materia-de-justicia-laboral
} 
radical de operador de justicia laboral, que se daría precisamente al festejar su primer Centenario nuestra Carta Magna de 1917.

Tras su rápida y no tan ríspida discusión en el trabajo bicameral, en el Congreso de la Unión se aprobó reformar y adicionar dichos preceptos constitucionales anteriormente citados mediante el Decreto que, una vez aprobado por la mayoría de los Congresos locales del país, fuera promulgado en el Diario Oficial de la Federación (DOF) del 24 de febrero de 2017, entrando en vigor al día siguiente de su publicación. ${ }^{4}$ A la fecha en que esto se escribe, lo único cierto es que esta reforma constitucional está vigente en México, porque en el tema de su instrumentación legal, desde hace más de un año todo es rumor e incertidumbre.

En efecto, las reformas efectuadas a los artículos 107 y 123 Apartado A, de nuestra CPEUM, constituyen un hito histórico, un parteaguas jurídico que de alguna manera se aleja del clásico tripartismo laboral del Derecho del Trabajo nacional en la administración de justicia, al estar condenadas a desaparecer las Juntas Federal y Locales de Conciliación y Arbitraje, ${ }^{5}$ para ser sustituidas suponemos que en breve, en un plazo máximo de un lustro-, por Tribunales Laborales del Poder Judicial de la Federación y de las 32 entidades federativas del país, dependiendo ello de la competencia tanto material como territorial, acorde a lo establecido por la fracción XXXI del Apartado A, del artículo 123 Constitucional, el cual regula específicamente las relaciones laborales del trabajo ordinario-; lo que constituye un hecho inédito en el país donde surgieran por vez primera en el mundo los Derechos Sociales plasmados en una Constitución Política, en 1917.

\footnotetext{
4 Ver el texto íntegro de la aludida reforma a los artículos 107 y 123 Apartado A, en la siguiente liga web: http:// dof.gob.mx/nota detalle.php?codigo $=5472965 \&$ fecha $=24 / 02 / 2017$

5 En el Derecho Laboral mexicano, dichos tribunales administrativos fueron creados al expedirse la primera Ley Federal del Trabajo de 1931, publicada en el DOF del viernes 28 de agosto de 1931 y que entrara en vigor en todo el país el mismo día de su publicación atento a su artículo Primero Transitorio. No obstante, sus antecedentes primarios fueron: La Junta Federal de Conciliación y Arbitraje prevista en el artículo 358 y sigs.; las Juntas Centrales de Conciliación y Arbitraje, con sede tanto en el entonces Distrito Federal (hoy Ciudad de México), como en las capitales de las entidades federativas, establecidas en el artículo 343 y sigs.; ello sin dejar de mencionar a la Junta Federal de Conciliación, así como a las Juntas Municipales de Conciliación, figuras ambas ya extintas y que estaban previstas respectivamente en los artículos 352 y 336, todos los preceptos citados de la aludida Ley Federal del Trabajo original de 1931. Véase al efecto el DOF, en la liga web: http:// www.dof.gob.mx/nota to imagen fs.php? cod diario $=193390$ \&pagina $=3 \&$ seccion $=2$
} 
Acerca de este tema de cambio de operador de justicia laboral, convendría añadir que en los últimos años la propia Organización Internacional del Trabajo (OIT) venía insistiendo en cambiar radicalmente usos y costumbres ya obsoletos para el mundo actual, con el objetivo claro de que la función de justicia quedara en manos del Poder Judicial, a quien le corresponde en la clásica división de Poderes administrar justicia, a fin de ubicar al país en el contexto actual económico y social propio del siglo XXI; máxime cuando existe un mundo de economía globalizada, de evidente corte neoliberal, y México es, digamos, "el vecino incómodo" pero aun así socio comercial de los Estados Unidos de América en el «Tratado de Libre Comercio de América del Norte» (TLCAN), ${ }^{6}$ cuya revisión actualmente está en trámite y que junto con la construcción del muro fronterizo y la expulsión de migrantes mexicanos, son la crítica constante en la peculiar administración del Presidente Trump, a la cual hubo de responder directamente el Presidente Peña Nieto.

En tal contexto, el simple cuanto complejo hecho de trasladar íntegramente la operación de la justicia laboral a los Poderes Judiciales del país, con la consecuente desaparición de las rebasadas e inoperantes Juntas de Conciliación y Arbitraje, tribunales administrativos de clásica integración tripartita, integrados con representantes del sector Gubernamental, sector Patronal y sector de los Trabadores — los que dictaban laudos y no sentencias, porque no era el laboral un juicio sino en realidad un arbitraje, tal y como su nombre lo indica-, significa un tema de cambio radical en materia de impartición de justicia en MéxicoY que conste desde ahora: el cambio de operador de justicia no sólo es en materia laboral, sino de manera extensiva también en materia de conflictos por prestaciones en materia de seguridad social, como luego veremos.

Cierto, casi nadie habla del tema referido en el párrafo precedente debido a que no se han terminado de comprender todavía los verdaderos alcances de la reforma constitucional referida, debiendo puntualizarse que si bien se trata de una reforma de índole laboral, la misma — sin siquiera ser mencionada una

6 Para el lector interesado en saber más acerca del TLCAN, consúltese el PDF en la liga web: https://idatd.cepal. org/Normativas/TLCAN/Espanol/Tratado de Libre Comercio de America del Norte-TLCAN.pdf 
sola vez en el texto del Decreto de reforma- implicará también una necesaria reforma legislativa en materia de seguridad social. Como tampoco se ha captado que dicha reforma Constitucional comentada no alude a la administración de justicia laboral de los servidores públicos federales, regulados por el Apartado B del propio artículo 123 de la CPEUM y, por lo tanto, seguirá operando igual el actual Tribunal Federal de Conciliación y Arbitraje, de integración tripartita y dependiente del Poder Ejecutivo, cuya estructura por cierto es similar a la de las Juntas Federal y Locales del mismo nombre.

La interrogante a responder aquí es obvia: ¿Por qué no se homologa la administración de justicia laboral en ambos Apartados, si todos los prerreferidos Tribunales Laborales no forman parte del Poder Judicial, son de naturaleza administrativa y su fundamento es el artículo 123 de la CPEUM? La respuesta es más que evidente: por tener el Estado mexicano el total control político respecto de sus servidores públicos federales, siendo además el mayor empleador del país.

Por otra parte, la aludida reforma ha provocado diversas reacciones e irritación social profunda en los sectores involucrados en el tema laboral en estos tiempos convulsos que resiente el país por diversos factores, tales como las inminentes elecciones Presidenciales del país, que bien podrían trasformar la política económica y social de la nación; no es de extrañar entonces la reacción de molestia por la que sería la última reforma estructural del actual Ejecutivo Federal; máxime cuando el tema laboral es muy sensible a toda la población, ya acostumbrada a una peculiar administración de justicia regulada políticamente, desde hace un siglo, desde el Poder Ejecutivo Federal y el de las entidades federativas, generándose además una gran molestia en quienes consideraban a nuestras peculiares Juntas de Conciliación y Arbitraje como parte histórica de nuestra idiosincrasia e identidad nacional laboral y hasta como "modelo de orgullo" en la administración de justicia propia del Derecho Laboral nacional.

El porqué de esta reacción tan crítica al Gobierno federal y al Congreso de la Unión, pensamos debe ser aquí contextualizado para su mejor comprensión, ya que los cambios radicales en el ámbito laboral preocupan y conciernen a la población entera. 
Para empezar, recuérdese que en la Constitución de Querétaro, promulgada el 5 de febrero y en vigor en México a partir del $1^{\circ}$ de mayo de 1917 , en su artículo $3^{\circ}$ se estableció el derecho social de la educación laica y gratuita; en el artículo 27, en el tema agrario, se dispuso terminar con los latifundios y comenzar el reparto de tierras para que la trabajasen los propios campesinos. Empero, lo más trascedente del Derecho Social mexicano y sin duda el de mayor impacto internacional, fue que en el artículo 123 se fijaron reglas puntuales para regular el empleo formal, junto con la obligación de la previsión social como mecanismo protector especifico de los operarios subordinados y su familia. Su histórico texto innovador fijó un contrato social laboral básico que protegía a la relación laboral por sobre la existencia del contrato de trabajo, surtiendo legalmente ambos presupuestos los mismos efectos.

Más todavía. El propio Constituyente Originario, para regular en todo el país el empleo subordinado, y para que el Estado tutelara y protegiera a los operarios con reglas legales niveladoras de las desigualdades naturales, redactó el texto de dicho precepto, dejándole al legislador secundario dos cosas: desarrollar en ley las reglas fijadas, sin contravenirlas; y determinar el Derecho Procesal Laboral respectivo.

Al punto, sostenemos que el trabajo informal no subordinado y su libertad para ejercerlo, sin más límites que su licitud o su restricción por resolución judicial, se halla plasmado en el artículo $5^{\circ}$ de la propia CPEUM de 1917, derecho que quedó integrado de inicio en el capítulo de las antes denominadas "garantías individuales", hoy en día sustituidas por los derechos humanos, reconocidos en el artículo $1^{\circ}$ de nuestra Carta Magna a partir del 10 de junio de 2011.

Respecto a lo anteriormente afirmado, apena reconocerlo, pero pocos han terminado por comprender por qué muchos de nosotros, los iuslaboralistas mexicanos, y este mundo feroz de economía globalizada, consideramos que debería haber en México un Código Laboral del Empleo, que regulase expresamente al Apartado A del artículo 123 de la CPEUM, aplicable al tema del empleo ordinario, con normas sustantivas y adjetivas laborales que hoy contiene la Ley Federal del Trabajo (LFT). 
Y paralelamente, deberíamos contar también con una Ley General del Trabajo, que reglamentara el primer párrafo del artículo $5^{\circ}$ de nuestra Carta Magna, regulando el derecho al trabajo no subordinado a un patrón - porque es un derecho humano-, enfocada al trabajo informal, el trabajo autónomo, los trabajadores independientes y los domésticos, así como a la microempresa (que en la vida real no son patrones sino trabajadores); máxime cuando estadísticamente está demostrado que el trabajo informal representa casi el $60 \%$ de la población económicamente activa. ${ }^{7}$ Ello es así porque toda la gente trabaja, y sin embargo no todos laboran subordinadamente a un patrón, siendo obvio que trabajo no es sinónimo de empleo.

Volviendo a nuestro original hilo de ideas, a partir de la citada reforma constitucional del 24 de febrero de 2017, inevitablemente habrá en México un antes y un después en materia de justicia laboral, aunque existirá ciertamente un lapso de ajuste jurídico paulatino que debe estar previsto en leyes reglamentarias.

No obstante, para la adecuada instrumentación del Decreto del Constituyente Permanente, sucede que en el Congreso de la Unión han existido un sinnúmero de problemas de la más diversa índole porque, aprovechando dicha reforma Constitucional, se ha dictaminado en el Senado el 23 de marzo de 2018, un Proyecto de Dictamen de las Comisiones Unidas de Trabajo y Previsión Social y de Estudios Legislativos, el cual consta de 339 páginas y se ha empantanado por razones políticas, económicas y sociales, Esto generó la casi total desaprobación por diversas organizaciones académicas, entre ellas la de la «Academia Mexicana de Derecho del Trabajo y de la Previsión Social» (AMDTPS), fundada en 1943 por el insigne Maestro Don Jesús Castorena y con 75 años ya de fructífera existencia, misma que ha contado en su membresía con ilustres juristas como los Dres. Mario de la Cueva, Alberto Trueba Urbina, Néstor de Buen Lozano, y un largo etcétera. ${ }^{8}$

7 Véanse datos actualizados a 2017, proporcionados por el Instituto Nacional de Estadística y Geografía (INEGI), en su último Boletín de Prensa del 13 de febrero de 2018, en la liga web: http://www.inegi.org.mx/ saladeprensa/boletines/2018/enoe ie/enoe ie2018_02.pdf

8 La AMDTPS, termina de publicar un desplegado en el diario nacional Excélsior, de su acuerdo plenario unánime denominado: «Declaración de la LVIII Asamblea Nacional del Trabajo de la AMDTPS, Ciudad Juárez 2018», donde fija, respecto del tema, diez peticiones concretas para ambas Cámaras del Congreso de la Unión y 
De manera que así se festejó el primer Centenario de nuestra Carta Magna: rompiéndose con paradigmas jurídicos laborales que la enorme mayoría de los mexicanos creía, sin razón, que eran intocables. No obstante, todos sabemos que el mundo evoluciona y se transforma de prisa, y la ciencia del Derecho le persigue para intentar regularle de la mejor manera, si bien la realidad es casi siempre más sabia y más veloz que la ciencia jurídica.

Desde luego pensamos que el cambio de operador de justicia laboral no es un tema menor. Lo confirma el hecho de que el propio Titular del Trabajo y de la Previsión Social federal (STPS), acerca de dicha reforma y tras confirmarse la aprobación de la misma por la mitad más uno de los Congresos locales de las entidades federativas del país -satisfaciéndose así el requisito previsto para ello en el artículo 135 de nuestra Carta Magna-, ${ }^{9}$ dijo que: “...se trata de la más ambiciosa reforma en materia laboral en cien años de vigencia del artículo 123 Constitucional...". ${ }^{10}$

Ahora bien, somos sabedores de dos certezas que conviene dejar plasmadas aquí. La primera, es que para la implementación de dichas reformas laborales desde hace años el Gobierno federal venía realizando consultas con interlocutores clave de los Sectores Patronal y Obrero del país, al través de sus respectivos consultores legales, haciéndolo con sospechoso sigilo, no en el qué sino en el cómo se pretendía la materialización legal de la reforma constitucional aludida; y la segunda certeza es, como lo demuestran los hechos, el que se aprovecharía dicha reforma y adiciones al artículo 123 Apartado A de la CPEUM,

de la propia Secretaría del Trabajo y de la Previsión Social federal, ofreciendo en ella la colaboración académica del iuslaboralismo nacional en la tarea pendiente de acometer... aunque ya se sabe que el tema laboral es más político que técnico.

9 Por cierto, los primeros 17 Congresos Estatales que aprobaron dicha reforma constitucional en materia de justicia laboral son, por orden alfabético: Aguascalientes, Campeche, Chiapas, Chihuahua, Coahuila, Estado de México, Hidalgo, Jalisco, Michoacán, Nayarit, Nuevo León, Quintana Roo, Sinaloa, Sonora, Tamaulipas, Tlaxcala y Zacatecas.

10 Véase la nota de Jorge Almazán: “Aprueban reforma de justicia laboral en 17 Estados”, Sección Política, Diario Milenio, versión digital electrónica del 6 de febrero de 2017, donde entrevista al entonces Secretario de Trabajo y Previsión Social federal, Alfonso Navarrete Prida — hoy Secretario de Gobernación —, en la siguiente liga web: http://www.milenio.com/politica/stps-justicia_laboral-alfonso_navarrete-estados-reforma_laboral$\underline{\text { milenio-noticias } 0 \text { 898110358.html }}$ 
para cambiar el actual procedimiento laboral de la Ley Federal del Trabajo para judicializarle, amén de comprender el cúmulo de trabajo que todo ello traería aparejado para la necesaria armonización legal nacional, y para eso la STPS federal creó en su organigrama la denominada: Unidad de Enlace de la Reforma del Sistema de Justicia Laboral. ${ }^{11}$

Las dudas que surgen al seno de las academias iuslaboralistas nacionales e internacionales e investigadores de la materia, de los litigantes, los docentes de las universidades públicas y privadas del país, así como de la población en general, harán que su instrumentación nazca bajo sospecha y ausente de la debida legitimación social. Por ello, ante tanta incertidumbre, hemos considerado conveniente fijar ahora nuestra postura académica, ante el inevitable impacto que dicha reforma traerá consigo, dejando en claro que, si bien se trata de una reforma en materia de justicia laboral, la misma — sin siquiera ser mencionada una sola vez en el texto del Decreto de reforma constitucional aquí referido-, necesariamente implicará también una reforma legislativa en materia de seguridad social, un tema que por razones metodológicas abordaremos aquí en otro apartado.

\section{Aspectos fundamentales de la reforma de 2017 a los artículos 107 y 123 apartado A, de la Constitución Política mexicana}

Pues bien, los principales aspectos de la citada reforma tienen características que nos llaman mucho la atención, y de ellas desarrollaremos enseguida tan sólo ocho grandes temas para fines ilustrativos de su enorme complejidad, a saber:

a) Para comenzar el análisis jurídico, se trata de una reforma estructural

11 Para mayores datos, véase más información acerca de este nuevo órgano de la STPF federal, en la siguiente liga web: https://www.gob.mx/stps/prensa/crea-stps-unidad-especial-para-transicion-de-juntas-deconciliacion-y-arbitraje 
importante en materia de justicia laboral, la que también involucra a la justicia en asuntos de seguridad social, pues en México, indebidamente, se les suele poner juntos en el mismo saco, toda vez que de origen, constitucional y legalmente, a pesar del notable avance científico-jurídico, seguimos teniendo como país serios problemas y confusiones conceptuales acerca del Derecho Social en nuestro sistema jurídico vigente, debido al manipuleo político. ${ }^{12}$ Recordemos que el artículo 123 es el único precepto de que consta el Título Octavo de la CPEUM, "Del Trabajo y de la Previsión Social", que no de seguridad social, pues se trata de dos sistemas protectores distintos aunque complementarios entre sí.

Además, es un hecho público y notorio que en el mundo entero y por multitud de razones la seguridad social tiende ya a deslaboralizarse debido a que la producción de bienes y/o de servicios se ha venido automatizando con rapidez mediante el uso industrial de robots, programados para operar con alta tecnología en esta «era del conocimiento» por el avance de las Tecnologías de la Información y la Comunicación (TIC's); lo que provocará, más temprano que tarde, la desaparición de plazas laborales para millones de individuos en la ahora llamada «Industria 4.0». Así, con el inevitable desplazamiento humano, disminuirán sensiblemente los habituales aportes tripartitos para el financiamiento de dicho servicio público especializado, provocando a futuro una mayor inviabilidad económica si no se busca otra fuente capaz de financiarlo, al ligarse a la seguridad social el llamado empleo decente. ${ }^{13}$

b) En el texto de dicha reforma constitucional comentada, si bien se crean nuevas instituciones administrativas de índole laboral, no se establecen aspectos de índole sustantivo ni procedimental laborales, pues lo que se hizo sustancialmente fue cambiar de operador la administración de justicia, limitándose a fijar principios de operación, pero omitiéndose establecer lo que se

12 Véase el artículo de Ángel Guillermo Ruiz Moreno, intitulado: "La Constitución Mexicana de 1917 y su peculiar vinculación con el Derecho de la Seguridad Social del siglo XXI", en la Revista de la Facultad de Derecho de México, Tomo LXVII, enero-abril de 2017, № 267, Universidad Nacional Autónoma de México, pp. 467-495. También puede ser consultado dicho ensayo en la liga web: http://dx.doi.org/10.22201/ fder.24488933e.2017.267.58905

13 Véase el libro de Ángel Edoardo Ruiz Buenrostro, intitulado: “Bases mínimas para una seguridad social universal. La unificación de los Seguros Sociales en México”. Editorial Porrúa, México, 2017. 
deberá hacer para materializarla a cabalidad; esto es, el Constituyente Permanente ordena el qué, dejándole al legislador ordinario - tanto federal como local-, resolver el problema que supone el cambio de operador de justicia, decidir el cómo, el cuándo y el cuánto.

Pensamos que en su instrumentación legal deben intervenir, necesaria y coordinadamente, los tres Poderes de la Unión federales y, además, también los tres Poderes de las 32 entidades federativas del país, lo cual de suyo supone un enorme desafío al haberse fijado por el Constituyente Permanente tan sólo el plazo de un año para hacerlo - contado a partir del 25 de febrero de 2017, atento al texto de los artículos Primero y Segundo Transitorios del propio Decreto de reforma constitucional- A la fecha en que esto se escribe, ya transcurrió dicho plazo y aún no han cumplido dichos Poderes Legislativos con el mandato constitucional.

c) La reforma comentada no se limita exclusivamente a cambiar de operador en la impartición de justicia laboral en todo el país, sino que, a la par, efectúa un evidente proceso de federalización o centralización del tema laboral colectivo, pues se establece en el artículo Sexto Transitorio del Decreto de reforma constitucional la obligación de que las Juntas de Conciliación y Arbitraje les transfieran los procedimientos, expedientes y documentos a su cargo a los Poderes Judiciales Federal y Locales; como también se ordena que se transfieran al denominado Centro de Conciliación federal los asuntos relacionados tanto con el Registro de Contratos Colectivos de Trabajo, como de Organizaciones Sindicales.

Es de esperar entonces que, en la legislación reglamentaria respectiva que se emita, se establezca una fecha límite para que las mencionadas Juntas de Conciliación y Arbitraje del país - tanto la federal como las locales - acaben con el rezago de expedientes en trámite a su cargo, tarea que deben concluir atendiendo las reglas procedimentales de la ley vigente actual; y una vez se resuelva el último asunto planteado ante ellas, dichas Juntas dejen de operar como impartidoras de justicia laboral y desaparezcan. Así, al comenzar los Poderes Judiciales competentes a recibir las nuevas demandas en materia laboral —en fecha aún 
por determinar en ley-, tendrán los jueces la obligación inexcusable de que las sentencias que emitan sean dictadas cumpliendo con los principios jurídicos de: legalidad, imparcialidad, trasparencia, autonomía e independencia; quedándonos claro que los genéricamente denominados "Tribunales Laborales del Poder Judicial", comenzarán de cero su labor y que contarán, además, con un renovado procedimiento laboral. ${ }^{14}$

d) Nos llama poderosamente la atención que se apueste tanto a la conciliación de los conflictos laborales como la forma ideal de disolverlos para evitar una resolución por la vía judicial —y lo mismo ocurre ya en otras materias jurídicas en el país-. La reforma constitucional ordena efectuar de manera obligatoria un procedimiento administrativo conciliatorio previo a la demanda judicial, mismo que deberá agotarse como condición sine qua non antes de acudir a demandar en los tribunales laborales. ${ }^{15}$

Para ello, en el texto de la previamente aludida reforma comentada, se ordena la creación de Centros de Conciliación, tanto a nivel federal como Locales en cada entidad federativa del país, los cuales serán organismos públicos descentralizados de la administración pública, tendrán personalidad jurídica y patrimonio propios, y su función conciliatoria será clave para que opere a plenitud la reforma en materia de justicia laboral.

e) Dichos Centros de Conciliación, como lo señala la propia reforma constitucional en comentario, contarán con plena autonomía técnica, operativa, presupuestaria, de decisión y de gestión. Y también — habrá que puntualizarlo con meridiana claridad—, su operación se regirá mediante diez

14 En el artículo $1^{\circ}$ de la vigente Ley Orgánica del Poder Judicial de la Federación, donde se describe a quiénes integran este Poder no aparecen los "Tribunales Laborales", en la fecha que se escribe este ensayo no existe aún dicha figura jurídica por lo que habrá que reformar su texto para darles cabida. Se puede consultar el texto de dicha legislación federal en la siguiente liga web: http://www.diputados.gob.mx/LeyesBiblio/pdf/172_190617.pdf

15 Hemos escuchado en foros académicos la crítica de que el procedimiento administrativo conciliatorio, forzoso y previo a la posible interposición de la demanda laboral, vulnera el artículo $8^{\circ}$ de la «Declaración Universal de los Derechos Humanos» de Naciones Unidas. Opinamos que no es así, porque la conciliación bien puede interpretarse como parte integrante del recurso efectivo para obtener justicia, máxime cuando la etapa conciliatoria es considerada parte del proceso de administración de justicia laboral mexicana, prevista en nuestra Ley Federal del Trabajo. Véase la web: http://www.un.org/es/documents/udhr/UDHR booklet SP web.pdf 
principios jurídicos, que son los siguientes: certeza, independencia, legalidad, imparcialidad, confiabilidad, eficacia, objetividad, profesionalismo, trasparencia y publicidad... y nosotros añadiríamos al elenco el principio jurídico de la buena $f e$, con el que debe operar todo sistema jurídico, así sea este tramo conciliatorio del procedimiento laboral de carácter administrativo.

Para conseguirlo, se prevé que su integración y funcionamiento se determine en leyes federales del Congreso de la Unión para asuntos de competencia federal y en leyes locales que cada Congreso de las 32 entidades federativas del país expidan soberanamente, para que cada uno las ejerza en esta materia tan socialmente sensible, en modo tal que, tanto el Estado mexicano como todas las entidades federativas del país, se hagan cargo de la solución de diferencias entre patrones y trabajadores subordinados en el ámbito conciliatorio, así como de la impartición de justicia laboral, cada cual — se reitera - desde su respectivo ámbito competencial federal o local, acorde a lo ordenado por la fracción XXXI inciso c), del Apartado A del artículo 123 de la CPEUM.

f) El Decreto de reforma constitucional que venimos comentando ordena crear el organismo público descentralizado de índole federal que tendrá a su cargo la función conciliatoria, pero que, a la par - y esto es absolutamente importante-, facultándole para que dicho Centro lleve el control único del registro de todos los contratos colectivos de trabajo celebrados en el pais; $\mathrm{y}$, de una buena vez, también llevará el registro de todas las organizaciones sindicales existentes en el territorio nacional.

Estas funciones son tan trascedentes que el propio Constituyente Permanente diseñó un complejo procedimiento para la designación transexenal de su Titular, procedimiento de selección cuyo texto se establece en tres párrafos y en cuyo nombramiento se contempla la participación proactiva de dos Poderes de la Unión: tanto del propio Titular de Ejecutivo federal, como del Senado de la República.

g) El citado Decreto de reforma constitucional fija además los lineamientos para cuestiones que atañen a la libertad de la negociación colectiva y sindical en nueva fracción añadida al texto de la CPEUM — la fracción XXII Bis-, 
ordenándole al legislador secundario asegurar en norma legal dicha libertad de negociación colectiva para cuidar los legítimos intereses de patrones y de los trabajadores sindicalizados, garantizando además, mediante diversos principios jurídicos, la genuina representatividad de las organizaciones sindicales - cuyos estatutos sindicales deberán ajustarse siempre a tal normativa constitucional-, así como para lograr certeza en la firma, el registro y el depósito de los contratos colectivos celebrados.

Asimismo, se prevé en dicha nueva fracción XXII Bis la manera de resolver conflictos entre sindicatos por la titularidad de un contrato colectivo, estableciéndose que el voto de los trabajadores sea personal, libre y secreto en la celebración de un contrato colectivo de trabajo, y en la elección de sus dirigentes; así, para obtener la celebración de un contrato colectivo y emplazar a huelga, se deberá acreditar que se cuenta con la representación legítima de los trabajadores sindicalizados.

h) Finalmente, con independencia de comentar que, con la reforma en materia de justicia laboral, además de expedir la legislación del Centro de Conciliación Federal — que se pretende denominar Instituto y no Centro, por razones que se ignoran, acaso por su estructura o para diferenciarlo de los Centros de Conciliación Locales - , se pretenden reformar diversas legislaciones de índole federal: las leyes Orgánica del Poder Judicial de la Federación, la de la Administración Pública Federal, la Federal de Entidades Paraestatales, la del Seguro Social, y la del INFONAVIT .

Por último, comentamos que son seis los artículos Transitorios del policitado Decreto de reforma objeto de análisis, preceptos que grosso modo intentan regular la inevitable desaparición de las Juntas de Conciliación y Arbitraje, tras encomendarse la tarea de administración de justicia laboral al Poder Judicial lo cual se hará paulatinamente-; y en el artículo Quinto Transitorio del mismo Decreto previene que los derechos laborales de los actuales funcionarios y empleados de las Juntas de Conciliación y Arbitraje serán respetados conforme a la ley. 
Reiteramos pues lo que ya dijimos en párrafos anteriores: el artículo Segundo Transitorio del Decreto constitucional al que nos hemos venido refiriendo, estableció el plazo de un año natural contado a partir del día siguiente de su publicación para realizar las adecuaciones legislativas, el cual venció el 25 de febrero de 2018, por lo que se ha incumplido ya. Así, lo más probable es que la reforma trate de ser instrumentada legalmente antes de que concluya el mandato del actual Presidente, porque es incuestionable que la reforma constitucional comentada ya está vigente.

\section{III . Las tareas pendientes por acometer por el Estado mexicano en materia de administración de justicia en seguridad social}

De las anteriores observaciones efectuadas se advierte ya que es equivocada la idea de que el Derecho de la Seguridad Social forma parte del Derecho del Trabajo, a manera, digamos, de un simple apéndice; porque si bien es cierto que muchos dan por descontado que la seguridad social se desgajó y adquirió desde hace casi ya un siglo la fisonomía y filosofía propia del Derecho del Trabajo, también lo es que cada una de dichas disciplinas jurídicas tiene su propio origen, objeto, metodología, sistemática y normativa legal, por lo que es errónea tal conclusión que acaso se deriva debido al inadecuado acomodo del Título Sexto, Del Trabajo y de la Previsión Social, integrado exclusivamente por un precepto: el legendario artículo 123 de la CPEUM de $1917 .{ }^{16}$

En nuestra opinión, acaso el mayor problema es que seguirán impartiendo en México justicia social operadores que en realidad no son expertos en la temática de la seguridad social, todo ello con consecuencias negativas tanto para asegurados y los derechohabientes de dicho servicio público especializado, como para los propios Seguros Sociales demandados, que para colmo de males

$16 \mathrm{Al}$ respecto y para mayores datos, puede el lector consultar el texto íntegro del ensayo de Ángel Guillermo Ruiz Moreno, intitulado: "La Constitución Mexicana de 1917 y su peculiar vinculación con el Derecho de la Seguridad Social del siglo XXI", en la liga web de Revistas de la UNAM: http://dx.doi.org/10.22201/ $\underline{\text { fder.24488933e.2017.267.58905 }}$ 
no pueden legalmente conciliar intereses previo al juicio laboral, toda vez que en los proyectos de legislación secundaria no están facultados para conciliar - ni se pueden negociar tampoco los derechos prestacionales de los recipiendarios, al ser inalienables_-, pues los afectados al final no son nada más los asegurados o pensionados, sino su núcleo familiar dependiente económico de aquellos, pues la célula de la sociedad es la familia, entendida aquí como un grupo social.

Esos derechos humanos inalienables e irrenunciables, suelen serles denegados a sus recipiendarios de la seguridad social en actos definitivos de aparente índole administrativa aunque hayan cumplido con todos los requisitos de espera establecidos en ley para su otorgamiento formal y material - pensiones, subsidios, ayudas económicas, servicios sociales, atenciones médicas, guarderías, etc. - , muchas de las veces por simples lineamientos institucionales; por eso, al no haber conciliación posible, les son denegados dejándoles desamparados, por lo que habrán de esperar hasta la resolución del juicio respectivo, que puede durar años, para obtener lo que en justicia les correspondía y corresponde. Por lo que en este tipo de asuntos debería crearse por el legislador un procedimiento sumarísimo en vez de un simple juicio especial.

Importa esto sobremanera porque, derivado de la información oficial disponible ventilada por la propia STPS federal, uno de los diagnósticos situacionales más llamativos — por no decir que más preocupantes-, es que se detectó que alrededor del $60 \%$ de los asuntos que ventila y resuelve la Junta Federal de Conciliación y Arbitraje son demandas planteadas por asegurados, beneficiarios y derechohabientes, que reclaman con razón sus prestaciones en dinero o en especie de seguridad social; en eso fueron clave el diagnóstico conjunto de la investigación en materia de la Justicia Cotidiana laboral del CIDE, y los Diálogos continuos sostenidos en tal encomienda gubernamental. ${ }^{17}$

Habrá algunos juristas que opinen que sería mejor opción que los actos definitivos de los Seguros Sociales — que si bien son resoluciones de índole administrativo al emanar de un organismo público descentralizado, su naturaleza

17 "Diálogos por la Justicia Cotidiana. Diagnósticos conjuntos y soluciones". Gobierno de la República: http://www.gob.mx/cms/uploads/attachment/file/79028/Di logos Justicia_Cotidiana.pdf 
intrínseca es muy distinta-, las resolviera directamente el Tribunal Federal de Justicia Administrativa (TFJA), ${ }^{18}$ quien por cierto cuenta ya con todas las facultades competenciales para dirimir este tipo de conflictos, aunque se insiste: su naturaleza obviamente no es laboral, ni tampoco administrativa, sino en el fondo es un derecho social y a la par un derecho humano. Cierto es que el TFJA ventila juicios en materia de créditos fiscales de la seguridad social (las aportaciones de cuotas obrero patronales, capitales constitutivos y otros más, atento al artículo 2, fracción II, del Código Fiscal de la Federación, ${ }^{19}$ al ser el IMSS y el INFONAVIT organismos fiscales autónomos), pues son todas ellas resoluciones definitivas de índole administrativo y fiscal; dicho Tribunal —creado en 1937, regionalizado en 1978 para acercar la justicia al contribuyente-, luego se denominó: Tribunal Federal de lo Contencioso Administrativo y, en su natural evolución, por último obtuvo su denominación actual: TFJA.

Lo que más nos interesa comentar en este apartado es que la competencia para que la Junta Federal de Conciliación y Arbitraje conozca y resuelva los conflictos entre los recipiendarios de este servicio público especializado y el IMSS, se deriva del artículo 295 de la Ley del Seguro Social, precepto legal que diferencia plenamente la naturaleza jurídica de los actos definitivos del IMSS sobre prestaciones para sus afiliados, con respecto de las obligaciones de índole fiscal que son una responsabilidad patronal; ello es así aunque dicho precepto todavía mencione al Tribunal Federal de lo Contencioso Administrativo, aplicándose al efecto la adecuada e indispensable interpretación sistemática del tema.

Al punto, una acotación que desde luego no es dato menor. Dicho TFJA resuelve ya - aparte de los temas fiscales patronales del IMSS e INFONAVIT-, también temas prestacionales y pensionarios de seguridad social, pero no de trabajadores ordinarios sino de los empleados públicos federales afiliados al Instituto de Seguridad y Servicios Sociales de los Trabajadores del Estado

18 Para mayores datos de qué es y cómo opera el Tribunal Federal de Justicia Administrativa, véase su sitio web: http://www.tfjfa.gob.mx/

19 El artículo $2^{\circ}$, fracción II, del Código Fiscal de la Federación, puede ser consultado en la liga web: http:// www.diputados.gob.mx/LeyesBiblio/pdf/8 291217.pdf 
(ISSSTE),${ }^{20}$ al igual que de los miembros del ejército, fuerza aérea y naval armada del país - fuerzas armadas que también son servidores públicos federales, las que por razones de seguridad nacional no pueden estar en el mismo grupo asegurado que los civiles-, quienes están afiliados al Instituto de Seguridad Social de las Fuerzas Armadas Mexicanas (ISSFAM); ${ }^{21}$ todo ello, con la competencia prevista en el artículo 3 de la vigente Ley Orgánica del citado TFJA. ${ }^{22}$

En resumen, excepto los actos derivados de IMSS e INFONAVIT cuando ambos actúan en su carácter de persona moral oficial (que por lógica jurídica, tratándose de asuntos de Derecho Civil o Mercantil, tendrán dichos Seguro Sociales o bien las personas que con ellos contraten, otra jurisdicción disponible con tribunales competentes en dicha materia que diriman este tipo de acciones), el resto de los actos definitivos emitidos en las facetas de ambos Seguros Sociales federales citados como entidades aseguradoras nacionales, al ser organismos públicos descentralizados (regulada su actuación por el Derecho Administrativo) y, a la par, organismos fiscales autónomos (actos regulados por el Derecho Fiscal), corresponde revisarlos, para confirmarlos o anularlos, al citado TFJA, cuya jurisdicción administrativa es muy distinta a lo que en la reforma constitucional se les denomina genéricamente "tribunales laborales". ${ }^{23} \mathrm{Y}$ la competencia jurisdiccional, la determinará entonces el ámbito de actuación de dichos entes aseguradores nacionales precitados, debiendo conocer, por razones de competencia en esta sensible materia social, únicamente los Tribunales Especializados en Seguridad Social, del Poder Judicial de la Federación, pues al ser federal no podrán conocer de esta materia los Poderes Judiciales Locales.

Sin dejar de mencionar aquí que, por la importancia del tema de la

\footnotetext{
20 Véase el texto de la Ley del Instituto de Seguridad y Servicios Sociales de los Trabajadores del Estado, en la liga web: http://www.diputados.gob.mx/LeyesBiblio/pdf/LISSSTE_240316.pdf

21 Ver texto de la Ley del Instituto de Seguridad Social de las Fuerzas Armadas Mexicanas, en la liga web: http://www.diputados.gob.mx/LeyesBiblio/pdf/84 240517.pdf

22 Véase el texto completo de dicho artículo ${ }^{\circ}$ r de la Ley Orgánica del Tribunal Federal de Justicia Fiscal y Administrativa, en la liga web: http://www.diputados.gob.mx/LeyesBiblio/pdf/LOTFJA.pdf

23 Para comprender mejor las tres distintas facetas del IMSS e INFONAVIT, consúltense los capítulos VIII y IX, léase el libro de Ruiz Moreno, Ángel Guillermo, intitulado: Nuevo Derecho de la Seguridad Social. $14^{\mathrm{a}}$

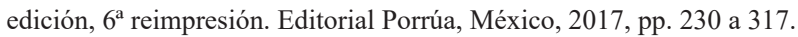


seguridad social, tal y como se ha hecho ya en otros países latinoamericanos (como un ejemplo claro, Argentina, que cuenta con jueces y jurisdicción especializada de seguridad social), ${ }^{24}$ opinamos que debería aprovecharse la oportunidad y crearse ya en México una jurisdicción especializada para efectuar una tarea de genuina justicia social en dicha materia, la que reiteramos es muy distinta del tema laboral, a fin de que el Estado mexicano cuente con juzgadores capacitados y expertos en el Derecho de la Seguridad Social.

Con la ventaja adicional de que se descargarian de trabajo tanto a los nuevos tribunales laborales, como a las propias Juntas Especiales de la Federal de Conciliación y Arbitraje, las que seguirán operando durante el periodo de transición-, como también beneficiaría al ya también recargado TFJA, de asuntos en esta compleja disciplina, con la idea de que se administre justicia pronta y eficaz bajo los parámetros jurídicos propios del Derecho Social y los específicamente legales que atañen a la seguridad social.

Además, los actos administrativos, en razón de su naturaleza intrínseca, se basan en principios del Derecho Público de aplicación estricta, es decir, que por su propia naturaleza jurídica es siempre de observancia estricta la norma aplicable — en estos casos, de índole fiscal—, y eso supone que, de permitirlo el Estado, se desnaturalizaría el trato jurídicamente diferenciado a que propende el Derecho Social, de cuyo elenco forma parte integrante el Derecho de la Seguridad Social..$^{25}$

De allí que habrá que innovar, pensar distinto y repensar bien las ideas para reconstruir, sustantiva y adjetivamente, nuestro actual sistema nacional de Seguridad Social, que ha sido rebasado ya por la dura realidad cotidiana. Y el punto focal del complicado tema estriba no tanto en la crisis de administración

\footnotetext{
24 Véase la conformación de las tres Salas de la Cámara Federal de Seguridad Social —ello sin contar a la Cámara Federal de Apelaciones de la Seguridad Social一, en la siguiente liga web: https://www.pjn.gov. ar/02_Central/Index2.Asp?Nodo=166\&Rubro $=2$

$25 \mathrm{Al}$ lector interesado en el tema del acto definitivo en esta materia, se le sugiere leer el libro de Ángel Guillermo Ruiz Moreno, intitulado: La impugnación legal de los actos definitivos del Seguro Social en México. Coedición de la Universidad de Guadalajara y el Instituto Jalisciense de Investigaciones Jurídicas. 1 ${ }^{\text {a }}$ edición, $1^{\mathrm{a}}$ reimpresión, Editorial Porrúa, México, 2012, pp. 108 y sigs.
} 
de justicia existente en materia de seguridad social en México, sino en la omisión de atender a las características propias de los llamados actos definitivos en esta materia, que sean susceptibles de impugnación por parte de los afectados en la vía jurisdiccional. Urge, pues, crear en México Juzgados de lo Social, con jueces especializados que atiendan temas específicos del Derecho de la Seguridad Social, el Derecho Ambiental, y hasta del Derecho Familiar, porque aquí en estos complicados temas, el asunto es social y no individual. ${ }^{26}$

Así las cosas. La reforma en materia de justicia laboral se encuentra en un dilema y en una encrucijada jurídica y social, que no es fácil de atender y de entender y vuelve complicada resolverla sin la ayuda de verdaderos expertos jurídicos que sean capaces de distinguir entre los actos definitivos de seguridad social que derivan directamente de una relación laboral - como lo son las prestaciones en dinero y en especie de los trabajadores subordinados y/o sus beneficiarios, en las ramas del seguro de Riesgos de Trabajo y del seguro de Guarderías - ambas ramas del Régimen Obligatorio-, a los cuales remite de manera expresa la LFT y cuyo cumplimento se le derivó a la Ley del Seguro Social; distinguiéndoles y diferenciándoles de las prestaciones que, en razón de su propia naturaleza intrínseca, realmente correspondan al ámbito de la seguridad social su solución jurídica. Cierto, parece confuso lo que se ha dicho, pero es que lo es... y habrá que comprenderlo bien para que no lo sea y se proceda en consecuencia.

\section{Breves conclusiones}

Resulta evidente que la reforma y adiciones del 24 de febrero de 2017 a los artículos 107 y 123 Apartado A de nuestra CPEUM tienen como finalidad mejorar la operatividad de la justicia laboral en pleno siglo XXI, sin el lastre del obsoleto tripartismo $\mathrm{y}$, sobre todo, sin la injerencia de factores políticos que durante un

26 Ruiz Moreno, Ángel Guillermo. La impugnación legal de los actos definitivos del Seguro Social en México. Op. Cit., pp. 294 y 295.

Nota: La propuesta de crear en México Juzgados de lo Social, data desde la tesis doctoral del autor y está en su obra escrita desde 2007. 
siglo influyeran en las decisiones que asumían los tribunales administrativos en sus laudos, a fin de conseguir una administración de justicia pronta, expedita, completa e imparcial, tal y como lo ordena el artículo 17 de nuestra Carta Magna.

La población entera —en especial los empleadores y los trabajadores-, esperan se materialice una verdadera justicia social en cada conflicto dirimido, por lo que la idea de fondo subyacente es corregir las evidentes fallas estructurales en tres puntos clave que se busca lograr con dicha reforma en materia de justicia laboral:

A) Confiar en la conciliación como medio ideal para disolver conflictos laborales, toda vez que en la práctica se cumplía más dicha etapa contemplada como una fase procedimental prevista en la LFT, como un simple trámite ante las Juntas de Conciliación y Arbitraje. Porque, si no funciona a cabalidad el procedimiento conciliatorio en los asuntos laborales, sencillamente no se conseguirá el objetivo trazado, elevándose con cada juicio planteado el coste del sistema de justicia laboral en perjuicio de todos. Haciéndose eficaz uso de los mecanismos alternos de solución de controversias no tendremos que saturar a los juzgadores de litigios, por lo cual urge capacitar y certificar al personal operativo contratado para ello, capaz de conciliar los intereses de las partes, antes de llegar al Poder Judicial.

B) Dar seguridad y certeza jurídica a todos los involucrados en problemas laborales, cuidando los intereses legítimos de empleadores y organizaciones sindicales, mediante un registro único de sindicatos y registro de todos los contratos colectivos de trabajo libremente negociados, evitándose así la eventual discrecionalidad de su registro. Para ello se creó el organismo público descentralizado federal específico, el que tendrá un marco jurídico regulatorio de su actividad cotidiana, que estará contenido en una legislación que se denominaría Ley del Instituto Federal de Conciliación y Registros Laborales, debiéndose en este tema legislar con prudencia y efectividad a fin de establecer reglas claras de observancia obligatoria para todos. Esto confirma que 
va en serio el Estado mexicano en lograr una mejor justicia laboral, pues se busca con ello acabar con los llamados "sindicatos blancos" y los usuales "contratos de protección", siendo un hecho público y notorio esta peculiar práctica laboral desde hace décadas en México, así se niegue constantemente su existencia.

C) Se confía darle plena seguridad jurídica al procedimiento de huelga, haciendo énfasis en los casos en que se plantee esta para obtener la celebración y/o titularidad de los contratos colectivos de trabajo, siendo uno de los grandes temas que el sector patronal específicamente - y la sociedad en general- celebran y agradecen de esta reforma constitucional, en aras de terminar así con la llamada "extorsión sindical" que ha sido, por desgracia, una práctica usual en México en agravio de pequeñas y medianas empresas (PyME's), que sin duda son las más numerosas e indefensas del país. También se busca asegurar la existencia de una libre negociación colectiva, garantizándole a los sindicatos establecer con plena libertad sus propios estatutos, y garantizándose el voto libre, directo y secreto de los trabajadores en la elección de sus dirigentes y ante un eventual caso de huelga

Concluiremos diciendo que si interpretamos objetivamente el Artículo Segundo Transitorio de dicho Decreto de reforma en materia de justicia laboral, en realidad no determina un plazo fatal ni perentorio al establecer el lapso de un año para que el Congreso de la Unión y las Legislaturas de las entidades federativas realicen las adecuaciones legislativas para su instrumentación plazo que venció ya el 25 de febrero de 2018-, máxime que dicho Transitorio no establece sanción alguna ante su eventual incumplimiento; y nos consta a todos los juristas que los llamados "tiempos legislativos" (sic), se miden y corren de manera diferenciada al tiempo real.

Hay muchos cambios por hacer que deben pensarse bien para instrumentar correctamente esta trascedente reforma, a fin de que no existan errores, lagunas ni contradicciones legales, todo lo cual, lo comprendemos, requiere de tiempo. Porque jurídicamente habrá que construirlo y reconstruirlo casi todo, pues implica 
que el Poder Legislativo federal corrija y adecúe múltiples legislaciones para armonizarlas con la reforma constitucional comentada en este ensayo; sin dejar de lado que tocará a los 32 Congresos Locales reformar sus actuales Constituciones Políticas y expedir las legislaciones necesarias para tal fin en todas las entidades federativas del país.

También implicará reformar las actuales legislaciones de los Poderes Judiciales, tanto de la Federación como las Locales, para que puedan operar en materia de justicia laboral y abocarse a la necesaria capacitación y selección de los jueces; en tanto que, para los Poderes Ejecutivo Federal y Locales, les toca establecer los lineamientos de los Centros de Conciliación y dotarles de la infraestructura física y humana, capacitando y eligiendo a los funcionarios conciliadores, así como expedir luego los reglamentos que den cuerpo y sentido a la trascendente temática de dejar en manos del Poder Judicial la operación de la justicia laboral; todo lo cual, aparte de cuestiones presupuestales por resolver, implicaba una tarea complicada para sacarla en el lapso de un año fijado por el Constituyente Permanente, por tratarse de un hecho histórico e inédito en México.

Si bien eso explica, no justifica la demora. Empero, aquí lo que más interesa es que al final se consiga el objetivo perseguido: que haya en el país una mejor impartición de justicia laboral y social, bajo los principios jurídicos del Derecho del Trabajo que tanto lustre dieran al país a lo largo de una centuria.

De alcanzarse el objetivo trazado, entonces habrá valido la pena el esfuerzo desplegado y la espera. ¡Que así sea por el bien de las generaciones actuales y las futuras de México! 


\section{Bibliografía}

\section{Libros consultados:}

Ruiz Buenrostro, Ángel Edoardo. Bases mínimas para una seguridad social universal: La unificación de los seguros Sociales en México. Editorial Porrúa, México, 2017,

Ruiz Moreno, Ángel Guillermo. La impugnación legal de los actos definitivos del Seguro Social en México. Coedición de la Universidad de Guadalajara y el Instituto Jalisciense de Investigaciones Jurídicas. Editorial Porrúa, México, 2012.

Ruiz Moreno, Ángel Guillermo. Nuevo Derecho de la Seguridad Social. Editorial Porrúa, 14 $4^{\mathrm{a}}$ edición, $6^{\mathrm{a}}$ reimpresión, México, 2017.

Ruiz Moreno, Ángel Guillermo. Artículo: "La Constitución Mexicana de 1917 y su peculiar vinculación con el Derecho de la Seguridad Social del siglo XXI". Revista de la Facultad de Derecho de México, Tomo LXVII, enero-abril de 2017, $\mathrm{N}^{\circ}$ 267, Universidad Nacional Autónoma de México.

\section{Sitios web consultados:}

www.gob.mx/cms/uploads/attachment/file/79028/Di_logos_Justicia Cotidiana.pdf

https://www.gob.mx/justiciacotidiana/documentos/iniciativa-dereforma-constitucional-en-materia-de-justicia-laboral http://dof.gob.mx/nota detalle.php?codigo $=5472965 \&$ fecha $=24 / 02 / 2017$ http://www.milenio.com/politica/stps-justicia_laboral-alfonso

navarrete-estados-reforma laboral-milenio-noticias 0898110358. $\underline{\mathrm{html}}$

https://www.gob.mx/stps/prensa/crea-stps-unidad-especial-paratransicion-de-juntas-de-conciliacion-y-arbitraje http://www.un.org/es/documents/udhr/UDHR_booklet_SP_web.pdf http://www.diputados.gob.mx/LeyesBiblio/pdf/172 190617.pdf 
http://www.stps.gob.mx/bp/secciones/junta federal/secciones/consultas/ reglamento.html

https://view.officeapps.live.com/op/view.aspx? src=http://www. diputados.gob.mx/LeyesBiblio/regla/n329.doc

http://www.diputados.gob.mx/LeyesBiblio/pdf/92_121115.pdf http://www.diputados.gob.mx/LeyesBiblio/pdf/125 120615.pdf http://www.ordenjuridico.gob.mx/TratInt/Derechos\%20Humanos/PI0. pdf

http://www.inegi.org.mx/saladeprensa/aproposito/2016/abogado2016 0 . pdf

http://www.ordenjuridico.gob.mx/TratInt/Derechos\%20Humanos/D50. pdf

http://www.gob.mx/cms/uploads/attachment/file/79028/Di_logos Justicia_Cotidiana.pdf http://www.tfjfa.gob.mx/ http://www.diputados.gob.mx/LeyesBiblio/pdf/LISSSTE_240316.pdf http://www.diputados.gob.mx/LeyesBiblio/pdf/84_240517.pdf http://www.diputados.gob.mx/LeyesBiblio/pdf/LOTFJA.pdf https://www.pjn.gov.ar/02 Central/Index2.Asp?Nodo=166\&Rubro=2 http://www.diputados.gob. http://www.diputados.gob.mx/LeyesBiblio/ pdf/8_291217.pdfmx/LeyesBiblio/pdf/1_240217.pdf

Cómo citar este artículo: Ruiz, Á. y Ruíz, Á. (2018). La instrumentalización de la reforma constitucional de 2017 en materia de justicia laboral y de seguridad social en México. Derecho Global. Estudios sobre Derecho y Justicia, 4 (10), pp. 127-152. 